\title{
EFEITO DO RESULTADO ABRANGENTE NOS INDICADORES DE DESEMPENHO DAS COMPANHIAS ABERTAS BRASILEIRAS ${ }^{1}$
}

\author{
EFFECT OF COMPREHENSIVE INCOME IN PERFORMANCE \\ INDICATORS OF BRAZILIAN LISTED COMPANIES
}

\author{
Geordana Mendonça Curcino \\ Graduada em Ciências Contábeis \\ Universidade Federal de Uberlândia (UFU) \\ geordana.mc@hotmail.com \\ Sirlei Lemes ${ }^{2}$ \\ Doutora em Controladoria e Contabilidade pela USP \\ Bolsista de Produtividade em Pesquisa do CNPq \\ Professora do Programa de Pós-Graduação em Ciências Contábeis da UFU \\ sirlemes@uol.com.br

\section{Reiner Alves Botinha} \\ Mestrando em Ciências Contábeis pela UFU \\ reiner.botinha@gmail.com
}

\section{RESUMO}

Visto que o Brasil está em pleno processo de convergência às Normas Internacionais de Contabilidade, o que pode ser verificado pelas alterações na Lei Societária e publicação contínua dos Pronunciamentos Técnicos do Comitê de Pronunciamentos Contábeis (CPC), o objetivo do presente estudo é verificar o impacto da evidenciação do resultado abrangente nos valores de indicadores financeiros de rentabilidade, após a convergência das normas de contabilidade brasileiras para as normas internacionais. Para a realização da pesquisa, foi composta uma amostra com as companhias abertas brasileiras listadas no índice Bovespa (Ibovespa), sendo coletados dados dos relatórios financeiros dos anos de 2010 a 2012. Realizou-se cálculo dos indicadores financeiros Retorno sobre o Patrimônio Líquido (ROE) e Lucro por ação (EPS) sob dois resultados (lucros líquido e abrangente) e utilizou-se de método estatístico para averiguar se há diferença dos indicadores calculados de acordo com essas duas formas de mensuração do lucro. Nesse sentido, notou-se que, para a amostra, não houve diferença significativa entre o ROE e EPS calculados com base no lucro líquido e no abrangente. Não obstante, constatou-se que, de maneira isolada, algumas empresas passaram por grandes variações de ROE e EPS em função da forma de cálculo realizada. Por fim, o estudo evidenciou que, embora seja pouco utilizado para fins de análise financeira, o resultado abrangente pode interferir na interpretação de indicadores de rentabilidade, o que ocorreu para algumas empresas analisadas neste estudo. A pesquisa tenciona contribuir com estudos anteriores,

\footnotetext{
1 Artigo recebido em: 30/09/2014. Revisado por pares em: 03/11/2014. Segunda versão enviada em 22/11/2014. Recomendado para publicação em: 23/11/2014 por Orleans Silva Martins (Editor Geral). Publicado em: 28/11/2014. Organização responsável pelo periódico: UFPB.

2 Endereço: Rua Segismundo Pereira, S/N, Santa Mônica, UFU/FACIC, CEP 38408-000, Uberlândia/MG. DOI: http://dx.doi.org/10.18405/recfin20140302
} 
apontando impactos da divulgação do resultado abrangente nos indicadores de rentabilidade das empresas, assim como o atendimento das empresas à norma que exige a sua apresentação.

Palavras-chave: Resultado Abrangente. ROE. Lucro por Ação.

\section{ABSTRACT}

Since Brazil is in the process of convergence with international accounting standards, which can be verified by changes in corporate law and continuing publication of Technical Pronouncements of $\mathrm{CPC}$, the objective of this study is to verify the impact of the disclosure of comprehensive income in the values of financial indicators of profitability, after the convergence of brazilian accounting standards to international standard. To conduct the survey, a sample was composed with the brazilian public companies listed on the Bovespa index (Ibovespa), being collected data from financial reports of the years 2010 to 2012. It was realized calculation of financial indicators Return on Equity (ROE) and Earnings per share (EPS) under two accounting incomes (net income and comprehensive income) and it was used a statistical method to determine whether there is difference of indicators calculated in accordance with this two ways of profit mensuration. In this sense, it was noted that, for the sample, there was no significant difference between the ROE and EPS calculated based on net income and comprehensive income. Nevertheless, it was found that, in isolation, some companies passed for grand changes in ROE and EPS, depending on the type of calculation performed. Finally, the study showed that, although it is few used for financial analysis, the comprehensive income can interfere in the interpretation of indicators of profitability, what happened to some companies analyzed in this study. The research intends to contribute to previous studies, pointing impacts of disclosure of comprehensive income in the indicators of profitability, as well the compliance of companies to the rule that requiring their presentation.

Keywords: Comprehensive Income. ROE. Earnings per Share.

\section{INTRODUÇÃO}

O objetivo da contabilidade consiste em fornecer informação estruturada de natureza econômica, financeira, física, de produtividade e social, aos usuários internos e externos às entidades (IUDÍCIBUS; MARION, 2006). Assim sendo, a contabilidade tem sido um fator de destaque no âmbito empresarial, devido às várias mudanças ocorridas no cenário mundial decorrentes de fatores econômicos, o que tem propiciado novos rumos e desafios para a contabilidade (RESENDE; PINHEIRO; MAIA, 2011).

O Brasil está em pleno processo de convergência às Normas Internacionais de Contabilidade e isto pode ser verificado pelas alterações na lei societária e publicação contínua dos Pronunciamentos Técnicos do Comitê de Pronunciamentos Contábeis (CPC). Lemes e Carvalho (2010) sustentam que a alteração na lei societária e a utilização dos pronunciamentos do CPC colocam o Brasil em uma posição diferenciada em relação a outros países, fazendo com que, em pouco tempo, a Contabilidade Internacional e a Societária possuam o mesmo significado.

Levando-se em consideração que no Brasil a divulgação da Demonstração do Resultado Abrangente (DRA) passou a ser exigida a partir de 2010, por meio do Pronunciamento Técnico 26 do CPC, o tema escolhido para realização deste estudo é a evidenciação do lucro abrangente em companhias abertas brasileiras. Nesse contexto, Epstein, Nach e Bragg (2006 apud PINHEIRO; MACEDO; VILAMAIOR, 2012) relatam que a divulgação do lucro abrangente é importante, pois este demonstra melhor o desempenho das empresas que o lucro líquido, porque inclui todas as alterações patrimoniais do período, exceto aquelas oriundas de investimentos dos proprietários e distribuições.

Com base na análise de pesquisas anteriores, (COELHO; CARVALHO, 2007; KABIR; LASWAD, 2011; LIN; RONG, 2012), verifica-se que estudos estão explorando a forma de evidenci- 
ação do lucro abrangente e as diferenças entre este e o lucro líquido. Em outros trabalhos (GALLON et al.,2009; FERRARO, 2011; KABIR; LASWAD, 2011; RESENDE; PINHEIRO; MAIA, 2011; TURKTAS et al., 2013), o lucro abrangente foi utilizado para calcular indicadores de desempenho assim como o value relevance, a fim de compará-los com os resultados obtidos aplicando-se o lucro líquido nas fórmulas.

Ademais, uma pesquisa realizada por Dastgir e Velashani (2008) apontou que o lucro abrangente não é superior ao lucro líquido na avaliação do desempenho de empresas, considerando o retorno de ações e preço. Porém, o trabalho publicado por Kanagaretnam, Mathieu e Shehata (2009) relatou utilidades do resultado abrangente, sendo sua mensuração significativamente associada com preço das ações e retornos de mercado.

A análise de pesquisas anteriores sobre o tema deste artigo aponta para a seguinte questão de pesquisa: a evidenciação do resultado abrangente impacta nos valores dos indicadores financeiros das empresas brasileiras após a convergência das normas de contabilidade brasileiras para as Normas Internacionais de Contabilidade? Nesse contexto, este estudo possui como objetivo geral de verificar o impacto da evidenciação do resultado abrangente nos valores de indicadores financeiros de rentabilidade após a convergência das normas de contabilidade brasileiras para as Normas Internacionais de Contabilidade.

Espera-se com o presente estudo apresentar possíveis impactos da divulgação da DRA nos resultados das empresas, de forma a incentivar àquelas que ainda não divulgam ou que estão iniciando a adoção às IFRS a cumprirem a norma estabelecida pelo IASB, bem como contribuir com a literatura sobre o resultado abrangente que ainda é incipiente.

A presente pesquisa foi estruturada em cinco seções. Após a primeira, representada pelos aspectos introdutórios, a segunda seção é constituída pela fundamentação teórica e versa sobre os principais conceitos acerca do tema. Em seguida, na terceira seção, são expostos os aspectos metodológicos, ressaltando as principais abordagens e amostra de empresas utilizada. Na quarta e quinta seções, são apresentadas, respectivamente, as análises dos resultados obtidos e as considerações finais sobre o estudo.

\section{REFERENCIAL TEÓRICO}

\subsection{Internacionalização das normas contábeis no Brasil}

O International Accounting Standards Board (IASB) é um órgão que guia países que pretendam adotar normas de contabilidade padronizadas, visando a uma maior uniformização da normatização contábil, pois ele publica e atualiza as Normas Internacionais de Contabilidade sob as siglas de IFRS (International Financial Reporting Standards) ou IAS (International Accounting Standards). Nessa perspectiva, Resende et al. (2011) asseguram que a convergência das demonstrações contábeis para o padrão IFRS permite aos investidores o acesso a relatórios contábeis comparáveis entre as empresas, diminuindo a assimetria informacional para o usuário externo das demonstrações contábeis.

De acordo com Viceconti e Neves (2011), a convergência das normas contábeis facilita a análise dos investidores internacionais, pois o manuseamento de demonstrações financeiras com normas distintas dificultava a comparabilidade e aplicação dos recursos por eles. Assim, os autores complementam que "a convergência é uma contribuição da classe contábil ao crescimento da economia global, pois viabiliza o fluxo de capitais e os investimentos oriundos do exterior" (VICECONTI; NEVES, 2011, p. 33).

Um dos fatores que propiciou a alteração radical no ordenamento contábil brasileiro, segundo Lemes e Carvalho (2010), foi o acatamento dos pronunciamentos do CPC pelas autoridades reguladoras governamentais. Ressalta-se que o CPC foi criado em 2005 pela Resolução CFC no 
1.055, visando à centralização e uniformização na emissão de normas e à convergência da contabilidade brasileira aos padrões internacionais.

Nesse sentido, o CPC vem emitindo uma série de Pronunciamentos Técnicos, que são homologados pelos órgãos competentes pela normatização contábil brasileira e passam a integrar o rol de normas seguidas pelas empresas. De acordo com Pinheiro et al. (2012), estes normativos buscam empenhadamente alternativas para fornecer informações que reflitam a posição financeira das instituições com maior fidedignidade. Entre os pronunciamentos emitidos está o CPC 26, o qual trata da apresentação das demonstrações contábeis e introduz uma nova demonstração na contabilidade brasileira: a Demonstração do Resultado Abrangente (DRA).

Destaca-se também que no Brasil o processo de convergência às Normas Internacionais de Contabilidade aconteceu, sobretudo, com a publicação das Leis no 11.638/07 e n⿳0 11.941/09, que alteraram dispositivos previstos na Lei das Sociedades por Ações ( $n^{\circ}$ 6.404/76). Nesse contexto, segundo Niyama e Rodrigues (2010), a internacionalização das normas de contabilidade tem como finalidade a harmonização dos padrões contábeis, mitigando as disparidades apresentadas nas demonstrações financeiras, melhorando, assim, a qualidade da informação contábil.

No processo de internacionalização das normas contábeis no Brasil, ainda se observam algumas divergências entre as normas editadas pelo CPC e a legislação societária vigente, a qual teve sua última atualização, em 2009, pela Lei no 11.941 . Um exemplo desta divergência é o tipo de demonstração financeira que será elaborada para apresentação do resultado do período das empresas. Nesse aspecto, de acordo com o art. 187 da Lei no 6404 (BRASIL, 1976), os resultados serão expostos na Demonstração do Resultado do Exercício (DRE), contendo as receitas e os rendimentos ganhos no período, independentemente da sua realização em moeda; e os respectivos custos, despesas, encargos e perdas, pagos ou incorridos. Assim, a Lei Societária, diferentemente do CPC 26, não dispõe sobre a divulgação da DRA.

\subsection{Evidenciação do Resultado do Período (DRE e DRA)}

Seguindo as Normas Internacionais de Contabilidade, Ernst \& Young e Fipecafi (2009, p. 24) afirmam que,

\footnotetext{
Uma entidade deve escolher uma das seguintes opções para apresentar seu resultado: (i) uma única demonstração do resultado abrangente; ou (ii) duas demonstrações separadas, sendo uma demonstrando os componentes do lucro ou prejuízo e outra começando com o lucro ou prejuízo, seguido dos componentes de outro resultado abrangente.
}

No Brasil, como mencionado, a DRA passou a ser exigida para as companhias abertas por meio do pronunciamento técnico CPC 26, a partir de 2010. No entanto, o CPC 26 não expõe as opções fornecidas pela norma internacional com relação à apresentação de uma ou duas demonstrações, sendo que, segundo este pronunciamento, a entidade deve evidenciar os itens de receita e de despesa em duas demonstrações: Demonstração do Resultado do período e Demonstração do Resultado Abrangente do período, sendo que esta última se inicia com o resultado líquido e inclui os Outros Resultados Abrangentes (CPC, 2011).

Segundo Lemes e Carvalho (2010), a DRA é composta pela DRE e Outros Resultados Abrangentes, os quais compreendem receitas e despesas reconhecidas diretamente no Patrimônio Líquido que não resultam de ações dos sócios como proprietários. Exemplos de Outros Resultados Abrangentes consistem nas alterações da reserva de reavaliação e os ganhos/perdas atuariais e de tradução de operações estrangeiras. Paralelamente, Santos e Schmidt (2011, p. 462), destacam que,

A DRA, além de apresentar a movimentação da conta de ajustes de avaliação patrimonial, informa o valor do resultado do período considerando-se, inclusive, os efeitos de ajustes de 
ativos líquidos mensurados a valor justo, ajustes de conversão de demonstrações contábeis, realização da reserva de reavaliação e ganhos e perdas atuariais de planos de benefícios de empregados, obtendo-se dessa forma o resultado abrangente do período.

Resumidamente, o lucro abrangente evidenciado na DRA é sistematizado na Figura 1, que demonstra os elementos e conceitos que devem ser considerados para sua apresentação.

Por meio da Figura 1, notam-se diferentes formas de mensuração do lucro, sendo que primeiramente é obtido o resultado das operações continuadas das empresas. Na sequência, são absorvidos a este lucro o resultado líquido das operações descontinuadas e os efeitos de erros e de mudanças nos princípios e padrões contábeis, chegando-se ao lucro líquido, o qual está associado ao funcionamento em continuidade da empresa, pois alcançam as mudanças ocorridas nos seus ativos, decorrentes de sua atividade (COELHO; CARVALHO, 2007).

Figura 1 - Composição do Lucro Abrangente.

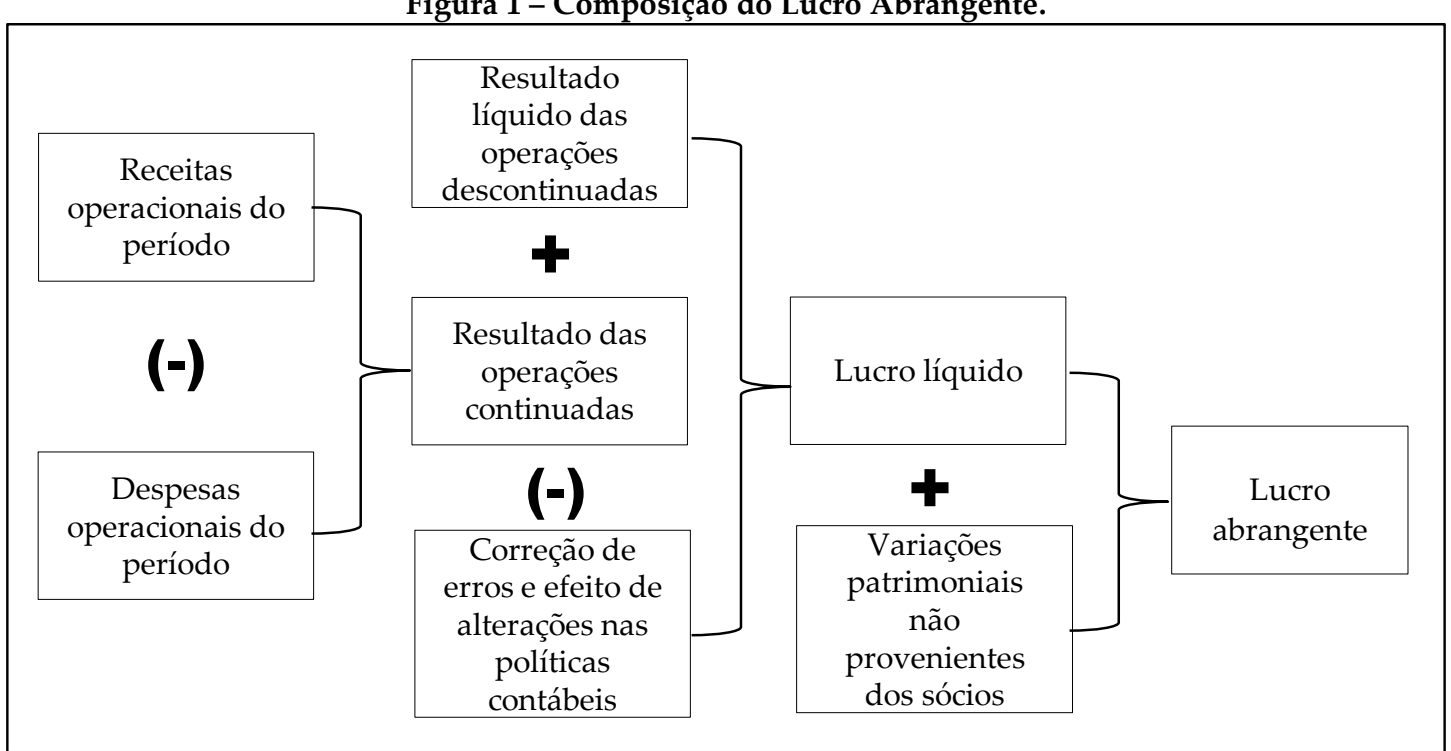

Fonte: Elaborado pelos autores.

Por fim, é somado ao lucro líquido outro evento, que de acordo com Coelho e Carvalho (2007) diz respeito a ganhos e perdas de natureza continuada ou fortuita que não foram realizados ainda no exercício corrente, mas cuja certeza de ocorrência seja alta, constituindo, assim, em variações patrimoniais não oriundas dos sócios. Tem-se, então, o lucro abrangente, que inclui na sua apuração todas as possíveis fontes de alteração da riqueza dos proprietários.

Nesse sentido, de acordo com Soutes e Schvirck (2006), existem diferentes formas de mensurar e evidenciar o lucro, as quais podem gerar informações muito divergentes, sem que nenhuma delas possa ser considerada errada do ponto de vista conceitual. Ademais, estes autores alertam para o fato de que os usuários das informações contábeis devem analisar se as informações disponibilizadas pelas empresas são suficientes, pois o formato no qual o resultado do período é divulgado interfere de maneira direta na informação necessária (SOUTES; SCHVIRCK, 2006). Isto pode ser verificado por meio da Figura 1, uma vez que existem diversos fatores que devem ser considerados na mensuração do lucro, seja ele líquido ou abrangente, e que podem interferir na análise da empresa.

Acerca dessa interferência do resultado abrangente na análise de uma empresa, existem estudos que analisaram algumas nuances quanto ao resultado abrangente, referente a seus principais reflexos, impactos e formas de evidenciação, frente às exigências emanadas pelos órgãos reguladores, conforme apresentado no Quadro 1. 
Quadro 1 - Estudos anteriores sobre resultado abrangente.

\section{Soutes e Schvirck (2006)}

Objetivos: Analisar quais são os Resultados: Pelo lucro contábil o investidor poderá avaliar o retorno avaliando a reflexos no ROA quando utilizadas eficiência da administração da empresa, podendo fatos alheios à atividade princidiferentes formas de mensuração do pal interferir diretamente no resultado obtido. Pelo lucro abrangente, são incluídas lucro, sendo tais formas, o lucro todas as variações ocorridas no PL da empresa no período exceto as movimentaoperacional contábil, lucro abran- ções de capital e a distribuição de dividendos aos acionistas, sendo indicada para o gente e lucro líquido.

\section{Kabir e Laswad (2011)}

Objetivos: Investigar as propriedades do Resultados: O estudo verificou que o lucro líquido é potencialmente lucro líquido e do resultado abrangente de mais persistente do que o lucro abrangente e, sem diferença significativa empresas da Nova Zelândia. Quatro proprie- na variabilidade e na capacidade preditiva entre as duas formas de lucro; dades são examinadas: a persistência, a varia- outros resultados abrangentes tem capacidade preditiva incremental, bilidade, a capacidade preditiva e o value embora não seja estatisticamente significativa, e os outros resultados relevance. abrangentes não geram acréscimos ao value relevance.

\section{Lin e Rong (2012)}

Objetivos: Verificar se a divulgação de outros Resultados: Os resultados mostram que outros resultados abrangentes resultados abrangentes tem efetivamente tem desempenhado um papel importante e afetou significativamente o melhorado a transparência da divulgação das gerenciamento de resultados, apontando que, a divulgação de outros empresas e, assim, efetivamente reduziu o resultados abrangentes é negativamente relacionada com o gerenciamengerenciamento de resultados. to de resultados.

\section{Pinheiro, Macedo e Vilamaior (2012)}

Objetivos: Analisar hipotética e empiricamen- Resultados: Os resultados obtidos apontam que as empresas brasileiras te a volatilidade que os Outros Resultados Abrangentes causariam, caso fossem registrados no resultado do exercício.

\section{Lee e Park (2013)} que negociam ações na NYSE confirmam a hipótese da alta volatilidade, sem tendência definida no sentido de aumento ou diminuição do Lucro. Verificou-se que a diferença entre a volatilidade do Lucro Líquido e a volatilidade dos Resultados abrangentes não é estatisticamente significativa.

Objetivos: Examinar empiricamente se a Resultados: Os resultados previram que o OCI de um cliente Big Four diferença de empresa de auditoria é refletida gera mais value relevance do que a de um cliente não-Big Four. De acordo no valor dos outros resultados abrangentes com as previsões, o OCI das auditadas por Big Four tem conteúdo de (OCI). Investiga se as medidas OCI de clientes informação incremental ao longo dos ganhos, em comparação com OCI Big Four geram maior value relevance do que auditadas por uma não-Big Four. Os resultados também mostram que o os de não Big Four. efeito de valorização diferencial entre Big Four e clientes não-Big Four é mais forte para os componentes OCI de natureza mais subjetiva.

\section{Mazzioni, Oro e Scarpin (2013)}

Objetivos: Avaliar o lucro líquido e o resulta- Resultados: Os resultados permitiram concluir que não há nenhuma do abrangente como medidas preditivas de evidência de que o resultado abrangente possui capacidade preditiva desempenho das empresas do setor elétrico superior ao lucro líquido para prever os resultados. Foram considerados que integram a BM\&FBovespa, a partir da como resultados futuros o retorno das ações, o lucro operacional, o fluxo volatilidade dos resultados encontrados no de caixa operacional, o lucro líquido consolidado e o resultado abrangenperíodo de 2010 e 2011. te do ano $t+1$, na amostra investigada.

Turktas et al. (2013)

Objetivos: Investigar se a escolha quanto a Resultados: Os resultados da pesquisa mostram que não existe uma forma do relatório de resultado abrangente é associação significativa entre a escolha de relatórios das empresas e do influenciada por fatores mencionados pela capital baseado em incentivos, segurança no trabalho, a volatilidade e a Teoria da Contabilidade Positiva e se os inves- alavancagem das empresas. Os resultados sugeriram que há uma associtidores valorizam a sua escolha, olhando para ação significativa entre a remuneração total do CEO e a volatilidade, de os retornos das ações das empresas do S\&P um lado, e a escolha de relatórios das empresas, por outro lado. No en350 Europe Index.

Fonte: Elaborado pelos autores. tanto, estes resultados não são significativos no sentido esperado, mas na direção oposta. 
Nesse mesmo prisma, a pesquisa busca contribuir com as pesquisas levantadas, apresentando os efeitos dos resultados abrangentes nos indicadores de desempenho ROE e EPS que serão discorridos na seção seguinte.

\subsection{Indicadores financeiros: Retorno sobre o PL (ROE) e Lucro por Ação (EPS)}

O Return on equity (ROE), ou Retorno sobre o Patrimônio Líquido, é o indicador mais conhecido da análise das demonstrações financeiras, e expressa o retorno financeiro líquido gerado pela empresa em função do capital investido pelos sócios (RESENDE et al., 2011). Martins, Diniz e Miranda (2012) complementam que o ROE é o mais importante dos indicadores, porque demonstra a capacidade de a empresa remunerar o capital que foi investido pelos sócios, sendo relevante utilizar o Lucro Líquido na fórmula, pois é o que sobra para os sócios.

De acordo com Damodaran (2004), o ROE examina a rentabilidade a partir da perspectiva do investidor em ações, relacionando o lucro líquido, após os impostos e despesas de juros, com o valor contábil do investimento em ações. Segundo Rossetti (2008, p. 75), o ROE “é de tal importância que alguns modelos foram desenvolvidos com o intuito de analisar a sua variação ao longo do tempo, compreendendo melhor quais os fatores que levam à redução ou o aumento da rentabilidade dos acionistas". Estudos anteriores (SOUTES; SCHVIRCK, 2006) supracitados (na seção 2.2), utilizaram também o ROE para verificar quais foram os impactos nos indicadores financeiros motivados pela apresentação da DRA.

O Earnings per Share (EPS), ou Lucro por Ação, por outro lado, é considerado um importante indicador de rentabilidade, especialmente para o mercado acionário, pois, por meio dele, é possível mensurar a rentabilidade de cada ação em determinado período, isto é, aponta o retorno de mercado da ação (ROSSETTI, 2008). Assaf Neto (2007) acrescenta que o Lucro por Ação é um indicador de grande utilidade para a avaliação por parte dos investidores das empresas, pois mede o ganho potencial de cada ação, embora não seja necessariamente realizado financeiramente. Assim, o EPS pode ser utilizado na análise das demonstrações contábeis para associar a quantidade de ações emitidas pelas companhias abertas brasileiras com o lucro gerado por elas. Em linhas gerais, enquanto o ROE adota o valor contábil do PL em sua totalidade, o EPS adota o valor de mercado da ação, ou seja, o retorno de mercado da ação.

\section{DESENHO DA PESQUISA}

O objetivo do presente estudo é verificar o impacto da evidenciação do resultado abrangente sobre indicadores financeiros de rentabilidade, após a convergência das normas de contabilidade brasileiras para as Normas Internacionais de Contabilidade. Desta forma, foram coletados dados das demonstrações financeiras de uma amostra de empresas brasileiras. Na sequência foram calculados os indicadores ROE e EPS, utilizando-se o lucro líquido nas fórmulas, e, em um segundo momento, valendo-se do lucro abrangente, conforme demonstrado no Quadro 2 a seguir.

Quadro 2 - Indicadores utilizados durante a pesquisa.

\begin{tabular}{|c|c|c|c|}
\hline Índice & Descrição & \multicolumn{2}{|c|}{ Fórmulas } \\
\hline ROE & $\begin{array}{c}\text { Retorno sobre o Patrimônio } \\
\text { Líquido (PL) }\end{array}$ & $\begin{array}{c}\text { Lucro Líquido } \\
\text { PL inicial do período }\end{array}$ & $\begin{array}{c}\text { Lucro abrangente } \\
\text { PL inicial do período }\end{array}$ \\
\hline EPS & Lucro por ação & $\frac{\text { Lucro Líquido }}{\text { № de ações }}$ & $\frac{\text { Lucro abrangente }}{\text { № de ações }}$ \\
\hline
\end{tabular}

Fonte: Elaborado pelos autores.

Adicionalmente, para caracterização da amostra, além da razão social da empresa, os seguintes dados foram coletados: segmento de negócio a que pertence; valores do lucro líquido, lucro abrangente e patrimônio líquido; e quantidade de ações. 
Durante a análise dos resultados, foram aplicados recursos estatísticos para determinar a estatística descritiva da amostra. Para analisar os dados, buscou-se primeiramente examinar a normalidade para as variáveis elencadas, a fim de identificar o teste mais adequado para ser aplicado. Assim, verificou-se que as variáveis apresentavam distribuição normal nos anos de 2010 a 2012, sendo aplicado o teste T de Student, o qual "avalia se as diferenças observadas entre as médias de duas amostras ocorreram por acaso ou se houve uma diferença verdadeira" (HAIR JR et al., 2005, p.297).

Nesse sentido, os resultados obtidos com os cálculos dos indicadores sob as duas perspectivas (lucro líquido e lucro abrangente) foram separados em dois grupos. Posteriormente, foi utilizado o método estatístico teste T de Student, pois pretendeu-se, neste trabalho, realizar a comparação da média dos valores dos indicadores financeiros num grupo (lucro líquido) com a média dessa variável noutro grupo (lucro abrangente).

Para alcançar os resultados pertinentes ao estudo, foram estabelecidas hipóteses, que segundo Hair Jr et al. (2005), servem para explicar e testar fatos ou fenômenos propostos por meio de evidência empírica. Dessa forma, foram testadas as seguintes hipóteses:

$\mathbf{H}_{0}=$ as médias dos indicadores financeiros calculados com base na ótica de lucro líquido e com base no lucro abrangente são iguais.

$\mathbf{H}_{1}=$ as médias dos indicadores financeiros calculados com base na ótica de lucro líquido e com base no lucro abrangente não são iguais.

Salienta-se que estas hipóteses foram construídas com base na pesquisa de Soutes e Schvirck (2006), que sugeriram, no estudo realizado por eles, que a forma de mensuração do lucro torna diferente os resultados dos cálculos de indicadores, influenciando na análise deles. Nessas perspectivas, estas hipóteses serão testadas por meio do teste T de Student, sendo estabelecido um nível de significância igual a 0,05 .

Para a realização desta pesquisa, foram utilizados os relatórios financeiros (DRE e DRA) divulgados pelas companhias abertas brasileiras, com ações negociadas na BM\&F Bovespa, e pertencentes ao Índice Bovespa (Ibovespa) que conforme a BM\&FBOVESPA (2013) "é o mais importante indicador de desempenho médio das cotações do mercado de ações brasileiro".

Dado a relevância do Ibovespa na determinação das empresas com maiores negociações na BM\&FBOVESPA, foram extraídas informações das demonstrações financeiras das 65 companhias listadas neste índice em junho de 2013. No entanto, foram selecionadas somente as empresas que divulgaram o lucro abrangente nos anos de 2010, 2011 e 2012, totalizando 39 empresas. Foram coletados dados desses anos, visto que o CPC 26 incluiu a DRA no rol das demonstrações a serem divulgadas pelas companhias abertas brasileiras em 2009, com aplicabilidade a partir de 2010.

\section{ANÁLISE DOS RESULTADOS}

Conforme mencionado, para efetivação deste estudo selecionaram-se, das 65 empresas listadas no Ibovespa, somente aquelas que apresentaram a DRA concomitantemente nos anos de 2010, 2011 e 2012, totalizando 39 instituições. De maneira geral, seguem, na Tabela 1 as divulgações realizadas por essas companhias quanto a apresentação da DRA e DRE.

Segundo exposto na Tabela 1, 2010 foi o ano com menor divulgação da DRA, e sugere-se que isto ocorreu porque este foi o primeiro ano da obrigatoriedade da divulgação da demonstração pelas companhias abertas brasileiras. Destaca-se também que em 2012, três anos após a obrigatoriedade de divulgação da DRA, existiam empresas que não a realizavam. 
Tabela 1 - Divulgações realizadas pelas 65 empresas pertencentes ao Ibovespa.

\begin{tabular}{lccc}
\hline & $\mathbf{2 0 1 0}$ & $\mathbf{2 0 1 1}$ & $\mathbf{2 0 1 2}$ \\
\hline Divulgação de DRE e DRA & 40 & 43 & 48 \\
Divulgação apenas de DRE & 25 & 22 & 17 \\
\cline { 2 - 4 } - Ausência de Outros Resultados Abrangente & 15 & 13 & 10 \\
- Não aderência ao CPC 26 & 10 & 9 & 7 \\
\hline
\end{tabular}

Fonte: Dados da Pesquisa.

Por meio das notas explicativas das companhias que não divulgaram a DRA verificou-se que algumas empresas apresentaram a demonstração zerada e alegaram que não possuíam Outros Resultados Abrangentes no período em questão, como demonstrado na Tabela 1. Por outro lado, outras instituições não justificaram a ausência da DRA no rol de divulgações realizadas, o que pode ser interpretado como uma não adequação das empresas às normas vigentes no CPC 26, que determina a evidenciação dos itens de receita e de despesa reconhecidos no período em duas demonstrações: DRE e DRA. Contudo, nota-se que a não aderência ao CPC 26, para tais empresas, tem diminuído no decorrer dos anos, sendo que em 2010, dez empresas não seguiram a norma, e em 2012 o número caiu para sete.

Em relação as 39 empresas que divulgaram a DRE e DRA nos 3 anos, verificou-se que algumas companhias apresentaram lucro líquido superior ao abrangente, e em outras ocorreu o inverso. De maneira geral, segue no Gráfico 1 a classificação das 39 empresas em relação ao maior lucro encontrado dentre os dois tipos em análise (líquido e abrangente).

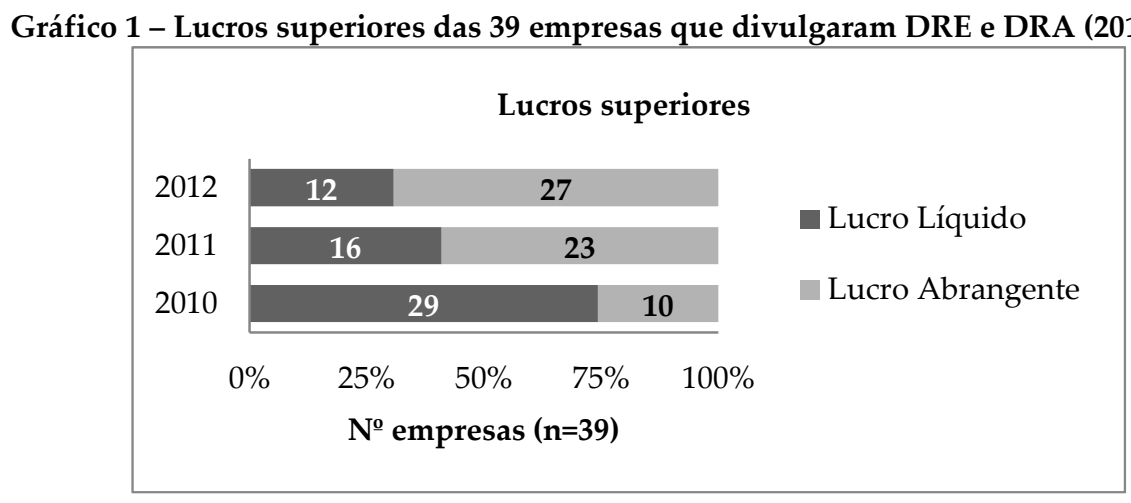

Fonte: Dados da pesquisa.

Por meio do Gráfico 1, percebe-se que em 2010 a maioria das empresas (29) possuía o Lucro líquido superior ao abrangente. Já em 2011 e 2012 ocorreu o inverso, sendo que a maior parte das companhias apresentou o Lucro abrangente superior. Nesse sentido, segundo Ferraro (2011), a inclusão de Outros Resultados Abrangentes no lucro da empresa pode gerar um impacto positivo ou negativo, fazendo crescer ou decrescer o resultado, levando até a inverter a posição de lucro para prejuízo, e vice-versa.

Dessa forma, a Tabela 2 mostra os impactos gerados (variações positivas ou negativas) pela adição dos Outros Resultados Abrangentes nos lucros líquidos das 39 empresas que divulgaram a DRA nos anos de 2010, 2011 e 2012.

Conforme a Tabela 2, as empresas podem ter variações positivas ou negativas em seus resultados por meio da divulgação da DRA. Em 2010, a maioria das instituições sofreram variações negativas em seus resultados, pois os Outros Resultados Abrangentes do período reduziram o lucro líquido do período ou acarretaram o crescimento do prejuízo. Em 2011 e 2012 a variação positiva no resultado prevaleceu dentre as empresas da amostra, pois a soma dos Outros Resultados Abrangentes ao lucro líquido provocou o crescimento do lucro, redução do prejuízo, e até mesmo, a inversão de prejuízo para lucro. 
Tabela 2 - Impactos dos Outros Resultados Abrangentes nos resultados das empresas.

\begin{tabular}{lccc}
\hline \multicolumn{1}{c}{ Impacto gerado } & $\mathbf{2 0 1 0}$ & $\mathbf{2 0 1 1}$ & $\mathbf{2 0 1 2}$ \\
\hline Variação negativa & \multicolumn{3}{c}{ Total de empresas (n=39) } \\
Lucro para prejuízo & $\mathbf{2 9}$ & $\mathbf{1 6}$ & $\mathbf{1 2}$ \\
Redução do lucro & - & - & - \\
Crescimento do prejuízo & 27 & 14 & 9 \\
\hline Variação positiva & 2 & 2 & 3 \\
Prejuízo para lucro & $\mathbf{1 0}$ & $\mathbf{2 3}$ & $\mathbf{2 7}$ \\
Crescimento do lucro & - & 1 & 1 \\
Redução do prejuízo & 10 & 18 & 21 \\
\hline
\end{tabular}

Fonte: Dados da pesquisa.

Na Tabela 3, estão listados os valores dos Outros Resultados Abrangentes das companhias (diferenças entre o lucro abrangente e líquido), a representatividade percentual destes sobre o lucro líquido, assim como o tipo de lucro que foi superior no período. Da amostra utilizada para este estudo, composta por 39 empresas, foram selecionadas as 10 companhias que apresentaram os maiores valores de Outros Resultados Abrangentes nos 3 anos de análise.

Tabela 3 - Maiores diferenças entre o Lucro Abrangente (LA) e o Lucro Líquido (LL) - Em R\$ milhões.

\begin{tabular}{|c|c|c|c|c|c|c|c|c|c|c|}
\hline \multirow[b]{2}{*}{ Empresa } & \multirow[b]{2}{*}{$\begin{array}{l}\text { Segmento } \\
\text { de negócio }\end{array}$} & \multicolumn{3}{|c|}{2010} & \multicolumn{3}{|c|}{2011} & \multicolumn{3}{|c|}{2012} \\
\hline & & $\begin{array}{l}\text { LA - LL } \\
\text { (ORAs) }\end{array}$ & $\%$ & $\begin{array}{c}\text { Lucro } \\
\text { superior }\end{array}$ & $\begin{array}{l}\text { LA - LL } \\
\text { (ORAs) }\end{array}$ & $\%$ & $\begin{array}{c}\text { Lucro } \\
\text { superior }\end{array}$ & $\begin{array}{l}\text { LA - LL } \\
\text { (ORAs) }\end{array}$ & $\%$ & $\begin{array}{l}\text { Lucro } \\
\text { superior }\end{array}$ \\
\hline Vale S.A. & $\begin{array}{l}\text { Minerais } \\
\text { Metálicos }\end{array}$ & -809 & $-3 \%$ & LL & 9.075 & $24 \%$ & LA & 9.829 & $106 \%$ & LA \\
\hline Banco Bradesco S.A. & Bancos & 384 & $4 \%$ & LA & -468 & $-4 \%$ & LL & 4.646 & $41 \%$ & LA \\
\hline $\begin{array}{l}\text { Cia Siderúrgica Naci- } \\
\text { onal }\end{array}$ & Siderurgia & 418 & $17 \%$ & LL & -1.199 & $-33 \%$ & LL & 1.753 & $365 \%$ & LA \\
\hline $\begin{array}{l}\text { Metalúrgica Gerdau } \\
\text { S.A. }\end{array}$ & Siderurgia & -708 & $-31 \%$ & LL & 1.063 & $54 \%$ & LA & 1.315 & $99 \%$ & LA \\
\hline Gerdau S.A. & Siderurgia & -695 & $-28 \%$ & LL & 1.062 & $51 \%$ & LA & 1.315 & $88 \%$ & LA \\
\hline $\begin{array}{l}\text { Cia Bebidas das Amé- } \\
\text { ricas }\end{array}$ & $\begin{array}{c}\text { Cervejas e } \\
\text { Refrigerantes }\end{array}$ & -482 & $-6 \%$ & LL & -384 & $-4 \%$ & LL & 1.692 & $16 \%$ & LA \\
\hline $\begin{array}{l}\text { Petróleo Brasileiro } \\
\text { S.A. }\end{array}$ & $\begin{array}{l}\text { Exploração } \\
\text { e/ou Refino }\end{array}$ & -24 & $0 \%$ & LL & 1.503 & $5 \%$ & LA & 742 & $4 \%$ & LA \\
\hline JBS S.A. & Carnes & -1.021 & $401 \%$ & LL & -189 & $59 \%$ & LL & 251 & $33 \%$ & LA \\
\hline Embraer S.A. & $\begin{array}{c}\text { Material } \\
\text { Aeronáutico } \\
\text { e Defesa }\end{array}$ & -252 & $-42 \%$ & LL & 670 & $391 \%$ & LA & 466 & $67 \%$ & LA \\
\hline Bco Brasil S.A. & Bancos & 168 & $1 \%$ & LA & 400 & $3 \%$ & LA & 607 & $5 \%$ & LA \\
\hline
\end{tabular}

Fonte: Dados da pesquisa.

Por meio da Tabela 3, destaca-se que a empresa com maiores divergências entre as duas formas de mensuração do lucro, pertencente ao segmento de Minerais metálicos, apresentou em 2011 e 2012 diferenças superiores a R\$ 9 bilhões, tamanha representatividade dos Outros Resultados Abrangentes nesses períodos. Tais diferenças superiores podem ser devido ao grau de investimentos mantidos no exterior, fator que agrega custos para a conversão das demonstrações contábeis conforme apontado por Pinheiro, Macedo e Vilamaior (2012).

Além disso, por meio desta tabela, observa-se que existem empresas cujos valores de Outros Resultados Abrangentes possuem alta representatividade quando comparados ao lucro líquido, como é o caso da Cia Siderúrgica Nacional em 2012 e da Embraer em 2011, onde os Outros Resultados Abrangentes representaram 365\% e 391\% do lucro líquido, respectivamente. Este fato 
converge ao estudo realizado por Lin e Rong (2012), que constataram que os outros resultados abrangentes, pela sua relevância, tem desempenhado um papel importante e afetado significativamente o gerenciamento de resultados.

Para dar continuidade ao estudo, e identificar o impacto dos Outros Resultados Abrangentes sobre o ROE e EPS, estes indicadores foram calculados sob as duas rubricas (lucro líquido e abrangente), conforme relatado na seção 3 deste trabalho. Nesse sentido, a Tabela 4 descreve a constituição da amostra utilizada para análise dos cálculos do ROE e EPS.

Tabela 4 - Amostra para análise do ROE e EPS.

\begin{tabular}{|c|c|c|}
\hline & ROE & EPS \\
\hline Empresas listadas no Ibovespa & & \\
\hline Empresas com lucro abrangente (2010-2012) & & \\
\hline Outliers eliminados & 7 & 1 \\
\hline Amostra (n) & 32 & 38 \\
\hline
\end{tabular}

Em relação ao cálculo do ROE, este foi realizado para as 39 empresas que divulgaram a DRA e DRE de 2010 a 2012, de acordo com as duas rubricas. Após esse cálculo, foram retiradas da amostra sete empresas, que foram consideradas outliers, pois diferiram em maior grau das médias das empresas da amostra, totalizando 32 empresas.

O mesmo procedimento foi aplicado para o cálculo do EPS para as 39 empresas que divulgaram a DRA e DRE de 2010 a 2012. Após o cálculo, foi retirada da amostra uma empresa, considerada outlier, totalizando 38 empresas componentes da amostra para cálculo do EPS.

Na sequência, foi aplicado o teste de normalidade para as 32 empresas da amostra do ROE e para as 38 companhias da amostra do EPS, e, em consequência dos resultados obtidos, verificouse a aplicabilidade do teste T de Student. Assim, as análises estatísticas realizadas nas companhias que divulgaram o lucro abrangente nos anos de 2010, 2011 e 2012 estão expostas na Tabela 5.

Tabela 5 - Teste $T$ para Diferença de Média com $95 \%$ de confiança.

\begin{tabular}{|c|c|c|c|c|c|}
\hline \multirow{2}{*}{ Período } & \multirow{2}{*}{ Lucro } & \multicolumn{2}{|c|}{ ROE (n=32) } & \multicolumn{2}{|c|}{ EPS $(n=38)$} \\
\hline & & Média & P-value (Teste T) & Média & P-value (Teste T) \\
\hline \multirow{2}{*}{2010} & Líquido & 0,1705 & \multirow{2}{*}{0,8449} & 2,0428 & \multirow{2}{*}{0,7641} \\
\hline & Abrangente & 0,1649 & & 1,9312 & \\
\hline \multirow{2}{*}{2011} & Líquido & 0,1338 & \multirow{2}{*}{0,8448} & 1,7592 & \multirow{2}{*}{0,7660} \\
\hline & Abrangente & 0,1426 & & 1,9229 & \\
\hline \multirow{2}{*}{2012} & Líquido & 0,0825 & \multirow{2}{*}{0,5290} & 1,0990 & \multirow{2}{*}{0,5108} \\
\hline & Abrangente & 0,1020 & & 1,3982 & \\
\hline
\end{tabular}

Fonte: Dados da pesquisa.

Os valores encontrados no teste T são os p-value ou valor de $p$, pelos quais é possível verificar se houve, ou não, diferença entre os cálculos dos indicadores financeiros por meio do Lucro Líquido e por meio do Lucro Abrangente. Para a análise, ressalta-se que o nível de significância adotado foi $5 \%$, visto que o teste considera um nível de confiança de $95 \%$.

Em relação ao cálculo do ROE, observa-se que, em todos os anos, o $p$-value ficou acima do nível de significância $(0,05)$, o que implica a aceitação da hipótese nula $\left(\mathrm{H}_{0}\right)$, que considera que as médias dos indicadores financeiros calculados com base na ótica de lucro líquido e abrangente são iguais nos três anos de análise (2010, 2011 e 2012). Esses resultados relacionados ao ROE corroboram os resultados encontrados por Resende et al. (2011), visto que os autores testaram as empresas brasileiras que publicaram na CVM as demonstrações contábeis referentes a 2009, e detectaram que a média do ROE, calculado a partir do Lucro Líquido ou Abrangente, não apresentava diferença. 
Gallon et al. (2009) buscaram identificar se a utilização do Lucro Abrangente para calcular os indicadores de desempenho ROA (indicador que mede o retorno sobre os ativos da empresa) e value relevance apresentariam resultados divergentes, no entanto, houve semelhança nos resultados, permitindo que o presente estudo corroborasse o estudo dos autores. O estudo de Kabir e Laswad (2011) apontou que o Lucro Líquido é potencialmente mais persistente do que o Lucro Abrangente, e que os outros resultados abrangentes não geram acréscimos ao value relevance.

Na pesquisa de Soutes e Schvirck (2006), os autores buscaram analisar quais eram os reflexos no ROA quando utilizado o lucro operacional contábil, o lucro abrangente ou o lucro líquido. Os autores identificaram que o lucro líquido seria a forma mais indicada, apresentando os efeitos das ações da administração sem o uso de eventos que não influenciam diretamente nos resultados da empresa, porém essa discrepância não foi encontrada na presente pesquisa.

Em relação ao EPS, o resultado foi semelhante ao ROE, uma vez que todos os valores de $p$ value estão acima do nível de significância de $5 \%$, fazendo com que se aceite a $\mathrm{H}_{0}$, e que se conclua que os valores do EPS calculado com base no lucro líquido e no lucro abrangente são significativamente iguais nos três anos de análise. Os resultados encontrados corroboram o resultado encontrado por Dastgir e Velashani (2008), os quais identificaram que, considerando o retorno e preço das ações, o lucro abrangente não é superior ao lucro líquido na avaliação do desempenho de empresas. Mazzioni, Oro e Scarpin (2013), analisando os métodos de apresentação do lucro enquanto medidas preditivas (utilizando o retorno das ações como variável de controle), concluíram que não há evidências que apontem o resultado abrangente como uma medida preditiva superior ao lucro líquido para prever os resultados. Tais estudos correlatos reforçam os resultados encontrados na presente pesquisa.

Contudo, os resultados contrastam com o trabalho realizado por Kanagaretnam et al. (2009), que evidenciaram que, nas empresas canadenses, o resultado abrangente é mais fortemente associado com preço das ações e retornos do que o lucro líquido, sendo um melhor indicador do lucro futuro. Nessa mesma perspectiva, os resultados encontrados nesta pesquisa divergem com o trabalho realizado, em 2011, por Ferraro, visto que no presente estudo não foram identificados impactos nos valores de indicadores financeiros causados pela forma de mensuração do lucro. Ferraro (2011) afirmou que a utilização dos Outros Resultados Abrangentes como parte do resultado ou como dados secundários, altera o desempenho podendo ter uma considerável influência na avaliação de indicadores.

Entretanto, analisando-se isoladamente as empresas, notou-se que estas expuseram variações nos valores dos indicadores financeiros calculados com base no Lucro líquido (LL) e Lucro abrangente (LA). Nas Tabelas 6 e 7, encontram-se as principais variações dos indicadores das empresas e os respectivos segmentos de negócios. Destaca-se que estão expressas, nessas tabelas, somente as 10 empresas que apresentaram maiores diferenças nos cálculos do ROE e EPS, realizados de acordo com as duas rubricas, visto que as demais companhias possuíram diferenças irrisórias.

Por meio da Tabela 6, observam-se as diferenças entre os valores dos indicadores calculados com base no lucro líquido e abrangente e a respectiva variação gerada no ROE pelo acréscimo dos Outros Resultados Abrangentes ao lucro líquido. Assim, as variações positivas representam que o ROE aumentou seu valor ao ser utilizado o lucro abrangente na fórmula, e o contrário ocorreu para as variações negativas. As maiores variações nos valores dos indicadores giram em torno de $400 \%$, sendo que há casos em que a companhia diminuiu seu indicador em $401 \%$ ao calculá-lo com base no lucro abrangente (JBS S.A.), e em outras houve aumento de 365\% (Cia Siderúrgica Nacional) e 391\% (Embraer S.A.) com o cálculo do ROE valendo-se do lucro abrangente. 
Tabela 6 - Variações entre o ROE (LA) e ROE (LL).

\begin{tabular}{|c|c|c|c|c|c|c|c|c|}
\hline & & & \multicolumn{6}{|c|}{ Diferenças absolutas entre ROE (LA) e ROE (LL) } \\
\hline & & & \multicolumn{2}{|r|}{2010} & \multicolumn{2}{|c|}{2011} & \multicolumn{2}{|c|}{2012} \\
\hline & Empresa & $\begin{array}{l}\text { Segmento de } \\
\text { negócio }\end{array}$ & Dif. & Variação (\%) & Dif. & Variação (\%) & Dif. & Variação (\%) \\
\hline 1 & $\begin{array}{l}\text { Cia Siderúrgica Nacio- } \\
\text { nal }\end{array}$ & Siderurgia & 0,063 & 17 & 0,153 & -33 & 0,208 & 365 \\
\hline 2 & Embraer S. A. & $\begin{array}{c}\text { Material Ae- } \\
\text { ronáutico e } \\
\text { Defesa }\end{array}$ & 0,050 & -42 & 0,128 & 391 & 0,080 & 67 \\
\hline 3 & Vale S.A. & $\begin{array}{l}\text { Minerais } \\
\text { Metálicos }\end{array}$ & 0,008 & -3 & 0,078 & 24 & 0,067 & 106 \\
\hline 4 & Metalúrgica Gerdau S.A. & Siderurgia & 0,033 & -31 & 0,058 & 54 & 0,054 & 99 \\
\hline 5 & Gerdau S.A. & Siderurgia & 0,032 & -28 & 0,053 & 51 & 0,050 & 88 \\
\hline 7 & Banco Bradesco S.A. & Bancos & 0,009 & 4 & 0,009 & -4 & 0,078 & 41 \\
\hline 8 & JBS S.A. & $\begin{array}{c}\text { Carnes e } \\
\text { Derivados }\end{array}$ & 0,053 & -401 & 0,010 & -59 & 0,012 & 33 \\
\hline 9 & Cosan S.A. Ind. e Com. & $\begin{array}{l}\text { Açúcar e } \\
\text { Álcool }\end{array}$ & 0,027 & -21 & 0,021 & 5 & 0,022 & 25 \\
\hline 10 & Marfrig Alimentos S.A. & $\begin{array}{c}\text { Carnes e } \\
\text { Derivados }\end{array}$ & 0,003 & -9 & 0,035 & 19 & 0,028 & 40 \\
\hline
\end{tabular}

Fonte: Dados da Pesquisa.

Assim, a empresa 1, que apresentou maiores diferenças no ROE pertence ao segmento de Siderurgia, destacando-se o fato de que, em 2012, ano com maior distorção, o ROE calculado com base no lucro abrangente ficou 20,8 pontos percentuais acima do indicador calculado utilizando-se o lucro líquido. Tomando-se a base teórica, apresentada anteriormente, o aumento do valor do ROE demonstra uma maior capacidade de a empresa remunerar o capital que foi investido pelos sócios (MARTINS; DINIZ; MIRANDA, 2012). Assim, infere-se que a forma de mensuração do lucro escolhida para se calcular o ROE pode interferir na análise econômica e financeira desta empresa.

A Tabela 7 traz as 10 empresas com maiores variações entre as duas formas de cálculo do EPS. Da mesma forma que o ROE, a empresa que apresentou maiores distorções pertence ao segmento de Siderurgia, sendo que, em 2012, o valor do EPS, sob uma forma de cálculo, aumentou em quase $100 \%$, fazendo com que os indicadores calculados de acordo com as duas rubricas apresentassem uma diferença de 318,7 pontos percentuais. Este fato pode interferir na análise desta empresa por parte dos acionistas, uma vez que, conforme mencionado anteriormente, o indicador EPS mede o ganho potencial de cada ação (ASSAF NETO, 2007).

De uma forma complementar, cumpre ressaltar que há estudos que apontaram a divulgação dos resultados abrangentes como inibidor das práticas de gerenciamento de resultados. Lin e Rong (2012) encontraram que outros resultados abrangentes afetaram significativamente o gerenciamento de resultados, inferindo que a divulgação de outros resultados abrangentes pode estar negativamente relacionada com o gerenciamento de resultados. Desta forma, torna-se necessário o estudo dos reflexos da apresentação dos resultados abrangentes frente aos principais problemas discutidos na literatura. 
Tabela 7 - Variações entre o EPS (LA) e EPS (LL).

\begin{tabular}{|c|c|c|c|c|c|c|c|c|}
\hline & \multirow[b]{3}{*}{ Empresa } & \multirow{4}{*}{$\begin{array}{l}\text { Segmento } \\
\text { Siderurgia }\end{array}$} & \multicolumn{6}{|c|}{ Diferenças absolutas entre EPS (LA) e EPS (LL) } \\
\hline & & & \multicolumn{2}{|r|}{2010} & \multicolumn{2}{|r|}{2011} & \multicolumn{2}{|c|}{2012} \\
\hline & & & Dif. & Variação (\%) & Dif. & Variação (\%) & Dif. & Variação (\%) \\
\hline 1 & Metalúrgica Gerdau S.A. & & 1,716 & -31 & 2,576 & 54 & 3,187 & 99 \\
\hline 2 & Vale S.A. & $\begin{array}{l}\text { Minerais } \\
\text { Metálicos } \\
\end{array}$ & 0,151 & -3 & 1,691 & 24 & 1,832 & 106 \\
\hline 3 & Bradespar S.A. & $\begin{array}{c}\text { Holdings } \\
\text { Diversificadas } \\
\end{array}$ & 0,029 & -1 & 1,530 & 26 & 1,101 & 81 \\
\hline 4 & Cia Siderúrgica Nacional & Siderurgia & 0,282 & 17 & 0,822 & -33 & 1,202 & 365 \\
\hline 5 & Embraer S. A. & $\begin{array}{c}\text { Material Ae- } \\
\text { ronáutico e } \\
\text { Defesa }\end{array}$ & 0,341 & -42 & 0,904 & 391 & 0,630 & 67 \\
\hline 6 & Gerdau S.A. & Siderurgia & 0,458 & -28 & 0,617 & 51 & 0,765 & 88 \\
\hline 7 & Banco Bradesco S.A. & Bancos & 0,102 & 4 & 0,122 & -4 & 1,215 & 41 \\
\hline 8 & Cosan S.A. Ind. e Com. & $\begin{array}{l}\text { Açúcar e } \\
\text { Álcool }\end{array}$ & 0,399 & -21 & 0,347 & 5 & 0,528 & 25 \\
\hline 9 & Energias do Brasil S.A. & $\begin{array}{l}\text { Energia } \\
\text { Elétrica } \\
\end{array}$ & 0,338 & -7 & 0,445 & -10 & 0,341 & -30 \\
\hline 10 & $\begin{array}{l}\text { Cia Bebidas das Améri- } \\
\text { cas }\end{array}$ & $\begin{array}{c}\text { Cervejas e } \\
\text { Refrigerantes }\end{array}$ & 0,155 & -6 & 0,123 & -4 & 0,541 & 16 \\
\hline
\end{tabular}

Fonte: Dados da Pesquisa.

Ressalta-se, por fim, que, para algumas empresas, o tipo de lucro escolhido para se calcular indicadores de rentabilidade pode interferir na interpretação de sua atual situação econômica e financeira. Ademais, não se pode assegurar qual das duas formas de mensuração do lucro (líquido ou abrangente) propiciará os maiores valores dos indicadores em estudo, e que isto dependerá das transações e situações específicas de cada entidade.

\section{CONSIDERAÇÕES FINAIS}

Com a criação de um novo padrão contábil brasileiro, por meio da convergência com as Normas Internacionais de Contabilidade, surgiram algumas contas e conceitos novos que mudaram o tradicional plano de contas. Dentre as alterações ocorridas, destaca-se a obrigatoriedade da divulgação do lucro abrangente, evidenciado na Demonstração do Resultado Abrangente, que é um relatório previsto nas IFRS, com reflexo nos CPC.

Considerando que o resultado abrangente inclui todas as mutações do PL (exceto as mudanças derivadas de ações com acionistas), incluindo o resultado do exercício, este estudo buscou verificar o impacto de sua evidenciação nos valores de indicadores financeiros de rentabilidade, após a convergência das normas de contabilidade brasileiras para as Normas Internacionais de Contabilidade, pressupondo como hipótese que as médias dos indicadores financeiros calculados com base na ótica de lucro líquido e com base no lucro abrangente não seriam iguais.

Em relação à aderência de companhias abertas brasileiras, listadas no índice Bovespa, às Normas Internacionais de Contabilidade, no que tange à divulgação do resultado abrangente, evidenciou-se que somente 39 empresas, de 65, divulgaram a DRA concomitantemente em 2010, 2011 e 2012. Além disso, os testes realizados apontaram que não existem impactos desta forma de reconhecimento do lucro sobre os indicadores financeiros de rentabilidade ROE e EPS, visto que não existem diferenças significativas entre os indicadores calculados sob as duas formas de mensuração do lucro (líquido e abrangente), ou seja, rejeitou-se a hipótese de que haveria diferença entre as médias dos indicadores com base no lucro abrangente.

Salienta-se que, embora os testes estatísticos realizados neste trabalho apontem para a igualdade entre as médias dos indicadores financeiros calculados com base no lucro líquido e abrangente, este estudo permitiu verificar que, individualmente, as empresas podem ser 
diferentemente interpretadas, caso recorram ao lucro líquido ou ao lucro abrangente para cálculo de indicadores de desempenho (ROE e EPS).

Não obstante, os resultados obtidos neste estudo permitem oferecer algumas reflexões sobre a utilização do resultado abrangente, tema ainda pouco explorado no Brasil em decorrência da recente relativa obrigatoriedade de divulgação. Por exemplo, atualmente não existe nenhum indicador financeiro nas referências tradicionais que utilize especificamente o lucro abrangente em sua fórmula, pois todos englobam outras formas de mensuração do lucro, tais como lucros líquidos e operacionais.

Com este estudo, espera-se ter contribuído para o aumento da discussão empresarial e acadêmica desse tema no Brasil. No meio empresarial, espera-se que as companhias abertas brasileiras busquem a divulgação da DRA, evidenciando informações completas e fidedignas conforme normas estabelecidas pelo IASB, com reflexo no CPC. Por sua vez, no meio acadêmico, espera-se que os resultados desta pesquisa tenham contribuído com a literatura e instiguem a construção de outras pesquisas científicas envolvendo o resultado abrangente.

Ademais, os limites do estudo consistem no fato de que foi analisado apenas o grupo de companhias abertas brasileiras pertencentes ao Ibovespa, que possuem ações com maior liquidez que as demais empresas. Dessa forma, a amostra selecionada não probabilística pode impedir a generalização dos resultados. Além disso, não foi escopo do trabalho identificar se existem outros fatores que impactam nos indicadores financeiros das empresas. Por fim, o último limite consiste no fato de que foram utilizados, para realização desta pesquisa, os índices financeiros que possuem Lucro Líquido nas fórmulas, de acordo com as referências tradicionais, o que restringiu a análise para o ROE e EPS. Não obstante, estes limites são inerentes ao objetivo deste estudo, e, possivelmente, trabalhos posteriores poderão detectar os potenciais efeitos de tais limites sobre os resultados apresentados.

Nesse sentido, a análise sobre o impacto dos Outros Resultados Abrangentes no desempenho das empresas requer um estudo mais aprofundado, visto que este trabalho identificou as diferenças entre lucro líquido e abrangente, mas não apurou os motivos de fato que fizeram tais lucros apresentarem variações. Nesse contexto, visando ampliar a discussão sobre essa nova demonstração contábil introduzida recentemente no Brasil, sugere-se a realização de pesquisas que envolvam outras companhias abertas brasileiras, listadas na BM\&F Bovespa, sobre a sua aderência às Normas Internacionais de Contabilidade, no que tange à divulgação do resultado abrangente, além da identificação e explicação de possíveis impactos desta forma de mensuração de lucro sobre outros indicadores financeiros de rentabilidade, como o ROA (Retorno sobre Ativo) e o ROI (Retorno sobre Investimentos).

\section{REFERÊNCIAS}

ASSAF NETO, A. Estrutura e análise de balanços: um enfoque econômico-financeiro. 8. ed. São Paulo: Atlas, 2007.

BM\&F BOVESPA - BOLSA DE VALORES, MERCADORIAS E FUTUROS DE SÃO PAULO. Índices. 2013. Disponível em: http://www.bmfbovespa.com.br. Acesso em: 31 mar. 2013.

BRASIL. Lei $n^{0}$ 6.404, de 15 de dezembro de 1976, Dispõe sobre as Sociedades por Ações. Disponível em: http://www.cvm.gov.br. Acesso em: 25 fev. 2013. 
COELHO, A. C.; CARVALHO, L. N. Análise Conceitual de Lucro Abrangente e Lucro Operacional Corrente: Evidências no Setor Financeiro Brasileiro. Brazilian Business Review, Vitória, v. 4, n. 2, p. 119-139, mai-ago. 2007.

CPC - COMITÊ DE PRONUNCIAMENTOS CONTÁBEIS. Pronunciamento Técnico CPC 26 - Apresentação das Demonstrações Contábeis (R1). 2011. Disponível em: http://www.cpc.org.br. Acesso em: 25 fev. 2013.

DAMODARAN, A. Finanças Corporativas: teoria e prática. 2 ed. Porto Alegre: Artmed, 2004.

DASTGIR, M.; VELASHANI, A. S. Comprehensive Income and Net Income as Measures of Firm Performance: Some Evidence for Scale Effect. European Journal of Economics, Finance and Administrative Sciences, v.12. p. 123-133, 2008.

ERNST \& YOUNG; FIPECAFI. Manual de Normas Internacionais de Contabilidade: IFRS versus normas brasileiras. São Paulo: Atlas, 2009.

FERRARO, O. Comprehensive Income in Italy: Reporting Preferences and Its Effects on Performance Indicators. Journal of Modern Accounting and Auditing, v. 7, n. 12, p. 1315-1328, 2011.

GALLON, A. V.; SILVA, T. P. da; TOLEDO FILHO, J. R. de; HEIN, N. Análise do ROA sobre as diferentes formas de apresentação do lucro nas empresas do nível 1 de governança corporativa da Bovespa. BASE - Revista de Administração e Contabilidade da Unisinos, v. 6, n. 1. p. 49-58, 2009.

HAIR JR, J. F.; BABIN, B.; MONEY, A. H.; SAMOUEL, P. Fundamentos de métodos de pesquisa em Administração. Porto Alegre: Bookman, 2005.

IASB - International Accounting Standards Board. IFRS: Consolidated without early application (Part B). London: IFRS, 2013.

IUDÍCIBUS, S.; MARION, J. C. Introdução à Teoria da Contabilidade. 4. ed. São Paulo: Atlas, 2006.

KABIR, M. H.; LASWAD, F. Properties of net income and total comprehensive income: New Zealand evidence. Accounting Research Journal, v. 24, n. 3, p. 268-289, 2011.

KANAGARETNAM, K.; MATHIEU, R.; SHEHATA, M. Usefulness of comprehensive income reporting in Canada. Journal Accounting and Public Policy, n. 28, p. 349-365, 2009.

LEE, C.; PARK, M. S. Subjectivity in fair-value estimates, audit quality, and informativeness of other comprehensive income. Advances in Accounting, incorporating Advances in International Accounting, n. 29, p. 218-231, 2013.

LEMES, S.; CARVALHO, L. N. Contabilidade Internacional para Graduação: texto, estudos de casos e questões de múltipla escolha. São Paulo: Atlas, 2010.

LIN, W.; RONG, M. Impacts of other comprehensive income disclosure on earnings management. Nankai Business Review International, v. 3, n. 1, p. 93-101, 2012. 
MARTINS, E.; DINIZ, J. A.; MIRANDA, G. J. Análise Avançada das Demonstrações Contábeis: uma abordagem crítica. São Paulo: Atlas, 2012.

MAZZIONI, S.; ORO, I. M.; SCARPIN, J. E. Lucro Versus Resultado Abrangente como Medida Preditiva do Desempenho das Empresas do Setor Elétrico Brasileiro. Registro Contábil, Maceió, v. 4, n. 3, p. 89-104, 2013.

NIYAMA, J. K.; RODRIGUES, J. M. Análise das demonstrações contábeis das companhias listadas na Bovespa: uma abordagem sobre os impactos decorrentes das modificações introduzidas pela Lei n. ${ }^{\circ}$ 11.638/07. Revista Brasileira de Contabilidade, Brasília, ano 34, n. 183, p. 25-38, 2010.

PINHEIRO, L. E. T.; MACEDO, R. P. de; VILAMAIOR, A. G. Lucro Líquido versus Lucro Abrangente: Uma Análise Empírica da Volatilidade. Revista Universo Contábil, Blumenau, v. 8, n. 4, p. 06$18,2012$.

RESENDE, L. L.; PINHEIRO, L. E. T.; MAIA, S. C. As diferentes formas de mensuração do lucro e o reflexo no ROE das empresas que aderiram ao padrão IFRS. In: SEMEAD, 14, 2011, São Paulo. Anais... São Paulo: USP, 2011.

ROSSETTI, J. P. (org). Finanças Corporativas: teoria e prática empresarial no Brasil. Rio de Janeiro: Elsevier, 2008.

SANTOS, J. L. dos; SCHMIDT, P. Contabilidade Societária. 4. ed. São Paulo: Atlas, 2011.

SOUTES, D. O., SCHVIRCK, E. Formas de Mensuração do Lucro e os Reflexos no Cálculo do ROA. Brazilian Business Review, Vitória, v. 3, n. 1, p 74-87, 2006.

TURKTAS, B.; GEORGAKOPOULOS, G.; SOTIROPOULOS, I.; VASILEIOU, K. Z. Reporting Comprehensive Income: Reasons for Reporting Choices and Investor Reactions. International Journal of Economics and Finance, v. 5, n. 4, p. 87-115, 2013.

VICECONTI, P.; NEVES, S. Contabilidade Avançada e Análise das Demonstrações Financeiras. 16. ed. São Paulo: Saraiva, 2011. 